\title{
Diversitas Gastropoda pada Akar Mangrove di Pulau Sirandah, Padang, Sumatera Barat
}

\section{Diversity of Gastropods on Mangrove Roots in Sirandah Island, Padang, West Sumatra}

\author{
Hirzan Riyandi ${ }^{1}$, Indra Junaidi Zakaria ${ }^{1 *}$, Izmiarti $^{1}$ \\ 1)Laboratorium Ekologi Hewan, Jurusan Biologi, FMIPA Universitas Andalas, Kampus Unand Limau \\ Manis Padang - 25163 \\ *Koresponden : indrajunaidi@,fmipa.unand.ac.id
}

\begin{abstract}
Currently, there are a lot of activities in Sirandah Island, such as tourism activities and deforestation to support the activities. Mangrove forest distruction makes a useable area might have negative effect to mangrove ecosystem itself or mollusc community. This research was conducted on mangrove roots area from February until October 2016. The aim of this research is to know the diversity of Gastropods on the roots of the mangrove. This research was conducted using survey method and purposive sampling method to collecting data. We recorded 8 genera of Gastropods belong to 8 families, named Cerithium, Conus, Ellobium, Littorina, Melongena, Nerita, Cymatium and Turbo. The highest abundance was found in the genus of Littorina with 59.33 individuals/tree. Based on location, abundance ranged from 4.33-60.33 individuals/tree with the highest abundance on mangrove roots of Barringtonia asiatica. Diversity indices of Gastropods on mangrove roots in Sirandah Island ranged from 0.77 to 1.42 which is relative low range.
\end{abstract}

Key words : diversity, gastropods, mangrove, mangrove roots

\section{Pendahuluan}

Ekositem mangrove merupakan tipe khas vegetasi daratan pesisir, memiliki ekosistem yang kompleks dan berfungsi sebagai zona penyangga bagi stabilitas ekosistem daerah vital lainnya di wilayah pesisir. Dikatakan sebagai ekosistem yang kompleks karena merupakan pertemuan antara ekosistem laut dan ekosistem daratan serta berperan penting sebagai tempat bermukimnya berbagai flora dan fauna (Kamal dkk., 2005). Hutan mangrove memiliki kontribusi yang besar terhadap detritus organik yang sangat penting sebagai sumber energi bagi biota yang hidup disekitarnya (Suwondo dkk., 2005).

Indonesia memiliki luas hutan mangrove terbesar di Asia Tenggara (75\%), namun akibat beberapa faktor, kondisi luas hutan mangrove mengalami penurunan (Giesen et al., 2007). Umumnya mangrove dapat dijumpai disetiap kepulauan Indonesia, salah satunya wilayah pesisir bagian barat sumatera khususnya Kota Padang yang memiliki luas areal mangrove sekitar 1.250.16 ha (Bapedalda Provinsi Sumatera Barat, 2011). Di wilayah pesisir Kota Padang terdapat beberapa pulau-pulau kecil yang memiliki ekosistem mangrove, salah satunya adalah Pulau Sirandah.

Di dalam hutan mangrove hidup berbagai jenis hewan dan tumbuhan mulai dari mikrobia, protozoa hingga yang berukuran besar seperti gastropoda. Gastropoda berasosiasi dengan ekosistem mangrove sebagai tempat hidup, tempat berlindung, memijah dan juga sebagai suplai makanan yang menunjang pertumbuhan mereka. Gastropoda ditemukan hidup pada daun, batang, ranting, akar dan lantai hutan mangrove.

Penelitian mengenai diversitas gastropoda di Sumatera sudah banyak dilakukan, diantaranya Dewiyanti (2004) melaporkan 11 famili dengan 22 spesies 
gastropoda ditemukan di area mangrove Ulee-Lheue, Banda Aceh. Dewiyanti and Karina (2012) melaporkan 14 spesies gastropoda ditemukan di area rehabilitasi ekosistem mangrove di Aceh Besar dan Banda Aceh, Indonesia. Kemudian Hartoni dan Agussalim (2013) melaporkan 17 spesies gastropoda ditemukan di ekosistem mangrove Muara Sungai Musi Kabupaten Banyuasin Provinsi Sumatera Selatan. Penelitian mengenai diversitas gastropoda pada akar mangrove di Pulau Sirandah, Padang, Sumatera Barat belum ada dilakukan.

Saat ini terdapat banyak aktivitas yang dilakukan di Pulau Sirandah seperti kegiatan pariwisata dan pembukaan lahan untuk menunjang kegiatan wisata. Perubahan kawasan hutan mangrove menjadi areal untuk kepentingan lain menimbulkan dampak negatif bagi ekosistem mangrove dan komunitas moluska. Menurut Alongi (2002), pembukaan lahan mangrove dapat mengakibatkan berkurangnya keanekaragaman fauna di ekosistem tersebut dan mempengaruhi keberadaan fauna yang mungkin tergolong endemik. Oleh Karena itu, informasi mengenai diversitas gastropoda sangat penting untuk stategi konservasi dan pengelolaan kelestarian serta keanekaragaman gastropoda dalam kegiatan pariwisata di Kota Padang, Sumatera Barat. Berdasarkan masalah diatas telah dilakukan penelitian dengan tujuan untuk mengetahui diversitas gastropoda pada akar pohon mangrove di Pulau Sirandah, Kota Padang, Sumatera Barat yang meliputi komposisi, kelimpahan, keanekaragaman, keseragaman, dan dominansinya.

\section{Metode Penelitian}

Penelitian ini dilakukan dari FebruariOktober 2016 di Pulau Sirandah, Kota Padang, Sumatera Barat dan Laboratorium Ekologi Hewan, Jurusan Biologi, Fakultas Matematika dan Ilmu Pengetahuan Alam, Universitas Andalas, Padang. Metode penelitian menggunakan metode survey, dan teknik pengambilan sampel menggunakan metode purposive sampling pada akar mangrove.

\section{Deskripsi Lokasi Penelitian}

Secara geografis lokasi penelitian terletak pada S $01^{\circ} 07^{\prime} 18,1^{\prime \prime}$ E $100^{\circ} 20^{\prime \prime} 24,2$ " dengan jarak sekitar $5 \mathrm{~km}$ dari daratan (Gambar 1). Terdapat empat zonasi pada pulau ini yaitu zonasi laut, zonasi pantai, zonasi pasir, dan zonasi hutan.

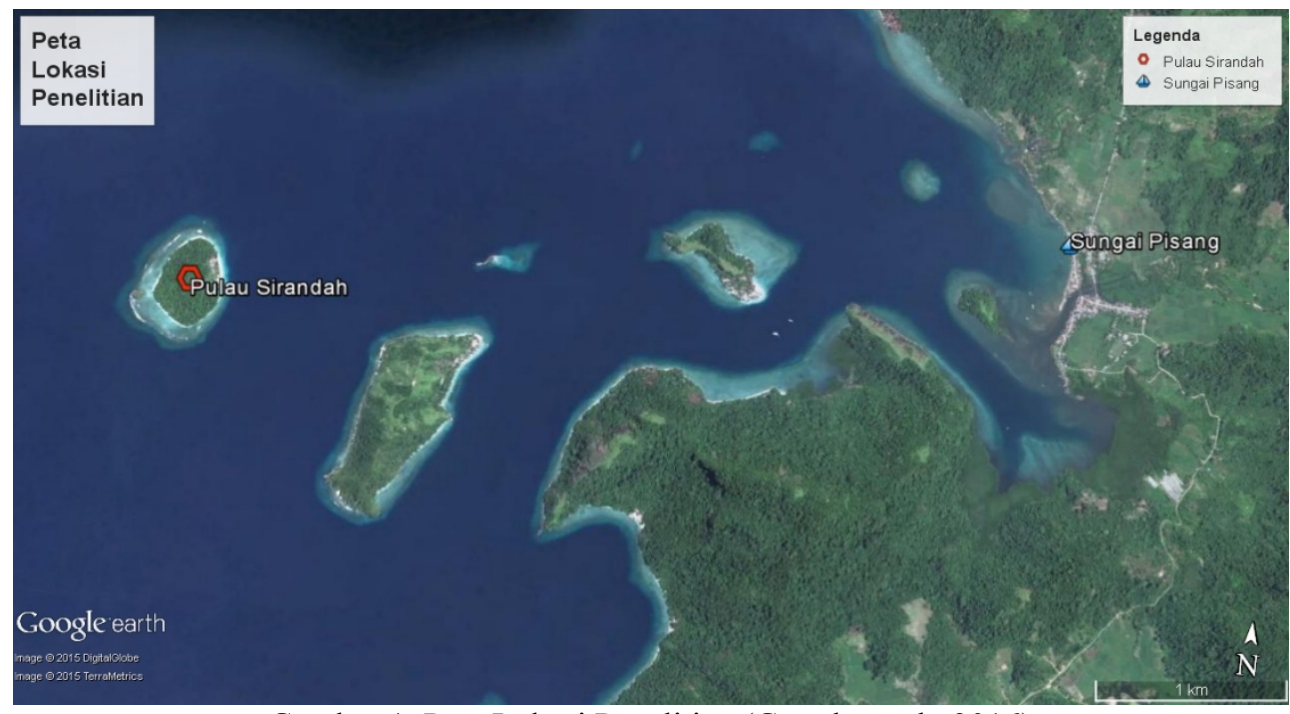

Gambar 1. Peta Lokasi Penelitian (Google earth, 2016)

Berdasarkan hasil survei lapangan mengenai kondisi lokasi, ditemukan beberapa jenis pohon mangrove yang berada pada daerah pasang-surut, diantaranya Barringtonia asiatica, Hibiscus tiliaceus, Pongamia pinnata. Lokasi akar 
pohon Hibiscus tiliaceus berada pada daerah pinggir bagian dalam yang berdekatan dengan tumbuhan ekoton, dan akar pohon Pongamia pinnata serta Barringtonia asiatica berada pada daerah pinggir bagian luar dekat tepi pantai, sehingga bagian akar pohon ketiga jenis mangrove ini terkena aktivitas pasangsurut.

Cara kerja

Di lapangan

Pada lokasi penelitian ditetapkan tiga jenis tumbuhan mangrove yang berada pada daerah pasang surut air laut. Masingmasing jenis mangrove diamati tiga jenis pohon mangrove untuk mempermudah pengamatan gastropoda yang ada pada perakaran mangrove. Semua jenis gastropoda yang diamati adalah yang berasosiasi dengan akar mangrove dari batas pasang terendah sampai batas pasang tertinggi. Sampel yang dikoleksi dimasukkan kedalam botol sampel yang telah diberi alkohol $70 \%$ dan diberi label data lokasi, waktu, dan tanggal pengkoleksian.

Faktor lingkungan yang diukur yaitu salinitas, substrat, suhu dan kelembaban. Pengukuran salinitas menggunakan handrefractosalinometer, Kemudian kelembaban diukur dengan menggunakan alat thermohygrometer dengan meletakkan alat tersebut di sekitar titik pengamatan.

\section{Di Laboratoium}

Hasil pengamatan langsung yang dilakukan di lapangan dilanjutkan dengan pengindentifikasian sampai tingkat genus dengan menggunakan beberapa buku panduan identifikasi, diantaranya yaitu: The living marine resources of the Western Central Pacific : Volume 1. Seaweeds, corals, bivalves and gastropods (Carpenter and Niem, 1998) dan Mollusca of The Indoaustralia Archipelago: Critical Revision of Javanese Freshwater Gastropoda (Jutting, 1956). Kemudian dilakukan analisis data.

\section{Analisa data}

Data yang didapatkan kemudian diolah untuk mendapatkan komposisi, kelimpahan per pohon (Brower and Zar, 1977). Kemudian dihitung indeks keanekaragaman, keseragaman, dan dominansi jenis gastropoda yang ditemukan pada masing-masing jenis mangrove tersebut (Odum, 1998).

\section{Hasil dan Pembahasan}

\section{Faktor Lingkungan}

Faktor lingkungan memiliki peranan penting bagi kehidupan makhluk hidup dalam proses perkembangannya termasuk gastropoda, oleh karena itu faktor lingkungan dianggap perlu untuk diukur dalam penelitian ini. Adapun parameter yang diukur saat pengambilan sampel yaitu meliputi suhu, kelembaban, salinitas dan tipe substrat (Tabel 1).

Tabel 1. Kisaran hasil pengukuran parameter lingkungan

\begin{tabular}{lcccc}
\hline \multirow{2}{*}{ Jenis Pohon } & \multicolumn{4}{c}{ Faktor Lingkungan } \\
\cline { 2 - 5 } & Suhu udara $\left({ }^{\circ} \mathrm{C}\right)$ & Kelembaban Udara (\%) & Tipe Substrat & Salinitas (\%) \\
\hline Hibiscus tiliaceus & $30-35$ & $44-66$ & Berpasir & $30-31$ \\
Pongamia pinnata & 31 & $58-69$ & Berpasir & 30 \\
Barringtonia asiatica & $29-31$ & $60-69$ & Berpasir & $29-30$ \\
\hline
\end{tabular}

\section{Komposisi dan Kelimpahan Genus}

Sebanyak 8 genera yang termasuk famili Cerithidae (1 genus), Conidae (1 genus), Ellobidae (1 genus), Littorinidae (1 genus), Melonginidae (1 genus), Neritidae (1 genus), Ranellidae (1 genus) dan Turbinidae (1 genus) ditemukan pada penelitian ini (Tabel 2). Gastropoda yang ditemukan pada lokasi penelitian pada umumnya hidup di permukaan substrat, melekat pada batu-batu dibawah pohon, akar dan batang pohon mangrove. Jenis yang paling umum ditemukan pada setiap 
lokasi akar mangrove adalah dari genus Littorina dengan kelimpahan total 59,33 individu/pohon. Berdasarkan lokasi kelimpahan berkisar antara 4,33-60,33 individu/pohon dengan lokasi tertinggi pada akar mangrove Barringtonia asiatica.

Tabel 2. Kelimpahan (individu/pohon) Gastropoda pada lokasi penelitian

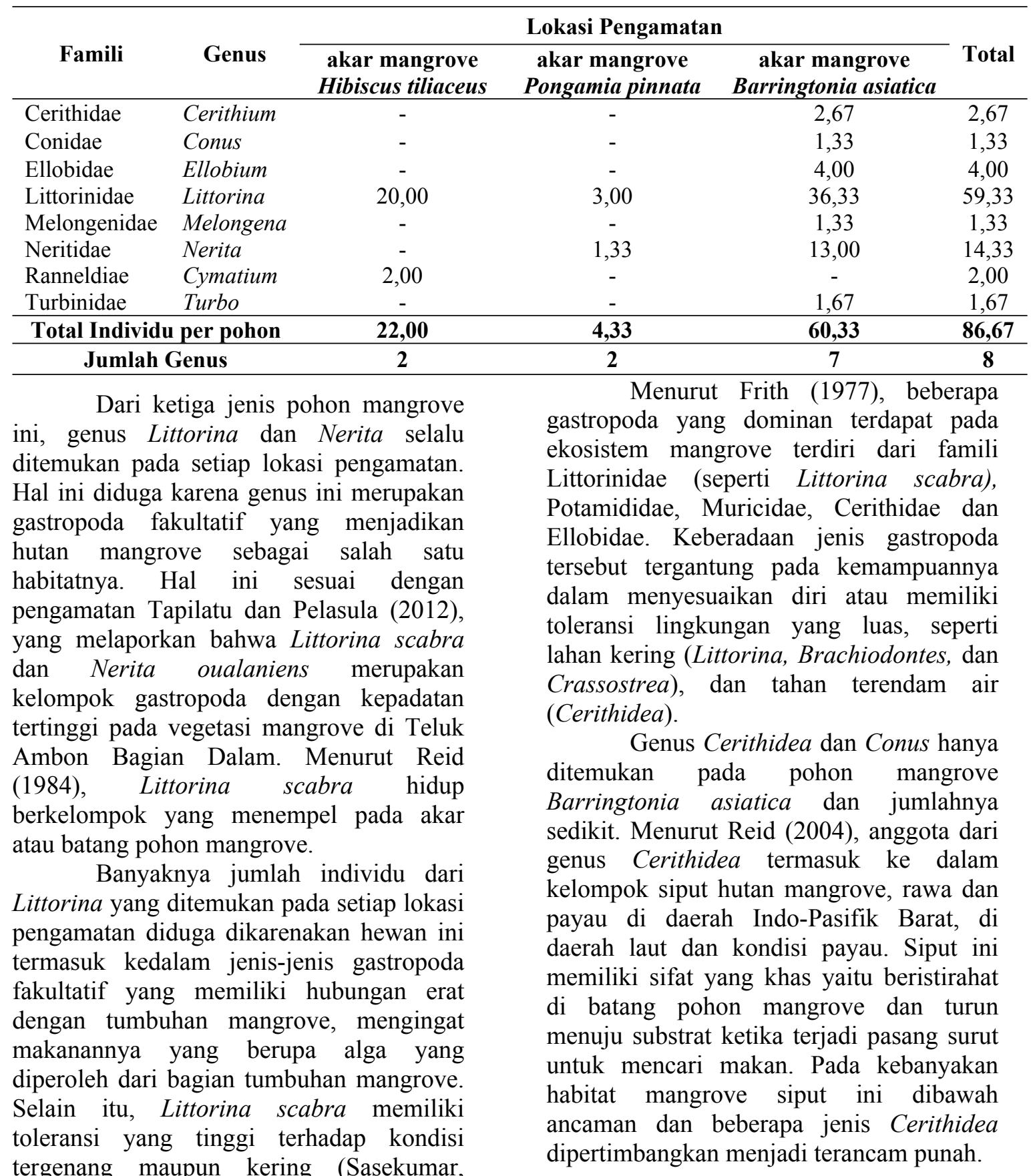
1974; Budiman, 1991; Blanco and Cantera, 1999). Penelitian Tis'in (2008), menunjukkan bahwa kepadatan gastropoda Littorina neritoides tinggi pada lingkungan dengan DO, dan salinitas yang tinggi, kerapatan yang tinggi serta substrat berpasir.

Indeks Keanekaragaman, Keseragaman dan Dominansi

Keanekaragaman dicirikan dengan tingkat keanekaragaman (H'), keseragaman (E), dan dominansi (C) dari suatu organisme. Selain mempunyai peran untuk 
menunjukkan kekayaan jenis dalam suatu komunitas, nilai-nilai tersebut dapat memperlihatkan keseimbangan dalam pembagian individu tiap jenis (Odum, 1998). Keanekaragaman berkaitan dengan dua hal utama, yaitu banyaknya jenis yang berada pada suatu komunitas dan kelimpahan dari masing-masing jenis tersebut. Pada hasil penelitian ini, setiap jenis pohon mangrove memiliki indeks keanekaragaman yang berbeda-beda seperti yang ditunjukkan pada Gambar 2.

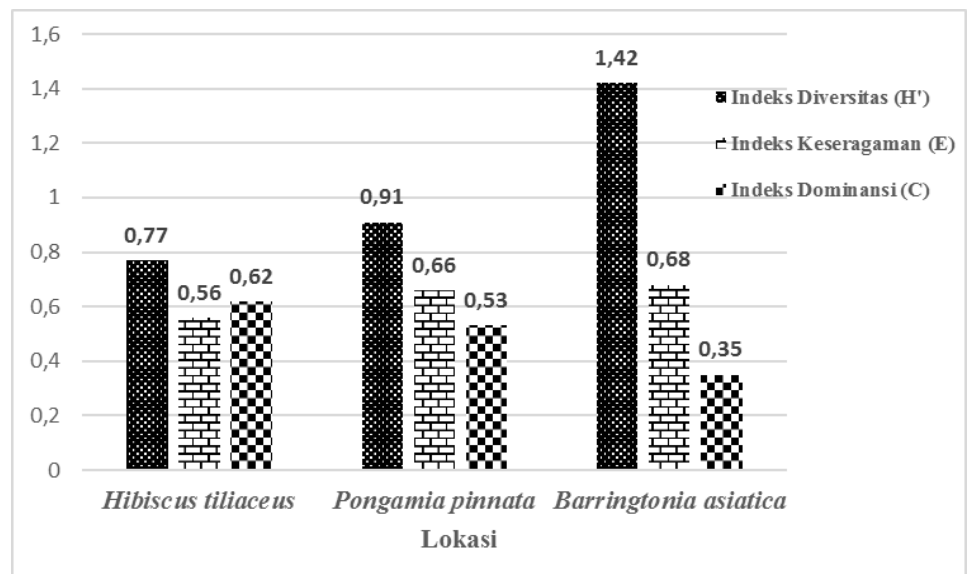

Gambar 2. Indeks Keanekaragaman $\left(\mathrm{H}^{\prime}\right)$, Keseragaman (E), dan Dominansi (C) fauna pada akar mangrove di Pulau Sirandah

Berdasarkan Gambar 2, nilai indeks keanekaragaman (H') gastropoda yang diperoleh pada masing-masing jenis pohon mangrove berkisar antara $0,77-1,42$. Pada lokasi pohon Barringtonia asiatica memiliki nilai indeks keanekaragaman tertinggi dengan nilai 1,42 , sedangkan yang terendah adalah pada lokasi pohon Hibiscus tiliaceus dengan nilai 0,77 . Hal ini menunjukkan bahwa setiap lokasi memiliki nilai keanekaragaman yang berbeda-beda, namun secara umum masuk kedalam kategori rendah kecuali pada lokasi akar pohon Barringtonia asiatica yang termasuk kedalam kategori sedang (Odum, 1998). Menurut Brower and Zarr (1977), faktor yang menentukan rendah tingginya nilai indeks keanekaragaman bukan hanya jumlah jenisnya saja melainkan juga ditentukan oleh kemerataan penyebaran populasi, yang dapat dilihat dari nilai indeks keseragamannya.

Tingkat keanekaragaman gastropoda pada penelitian ini berhubungan dengan indeks keseragaman dan indeks dominansinya. Secara keseluruhan nilai indeks keseragaman gastropoda pada akar mangrove di Pulau Sirandah berkisar 0,530,68. Hasil tersebut menunjukkan komunitas gastropoda pada lokasi tersebut populasinya tergolong kemerataan sedang dan namun labil. Nilai indeks keseragamanan dapat menunjukkan ada atau tidaknya dominansi suatu jenis pada suatu lokasi, sedangkan nilai indeks dominansi pengamatan berkisar antara $0,35-0,62$. Indeks dominansi yang mendekati nol berarti bahwa hampir tidak ada genus yang mendominasi genus lainnya walaupun beberapa spesies ditemukan dalam jumlah yang banyak (Magurran, 2004). Sehingga dapat dikatakan struktur komunitas dalam keadaan labil, dan tidak terjadi tekanan ekologis yang berlebihan terhadap biota dalam ekosistem tersebut.

Littorina ditemukan dalam jumlah besar, karena memiliki adapatasi yang baik terhadap lingkungan, tetapi bukan merupakan jenis yang dominan. Magurran (2004) menjelaskan bahwa jenis dengan jumlah tertinggi tidak berarti merupakan jenis yang dominan. Tinggi dominansi satu jenis mungkin mengindikasikan lingkungan stres sementara keragaman yang lebih tinggi menunjukkan kondisi yang stabil dari ekosistem (Machintosh et al., 2002).

\section{Kesimpulan}

Gastropoda yang ditemukan pada akar mangrove di Pulau Sirandah sebanyak 8 
famili yang terdiri dari 8 genera, yaitu Cerithium, Conus, Ellobium, Littorina, Melongena, Nerita, Cymatium dan Turbo. Kelimpahan total tertinggi didapatkan pada genus Littorina dengan 59,33 individu/pohon pada lokasi akar mangrove Barringtonia asiatica. Berdasarkan lokasi akar mangrove yang diamati, kelimpahan berkisar antara 4,33-60,33 individu/pohon.

\section{Daftar Pustaka}

Bapedalda Provinsi Sumatera Barat. 2011. Status Lingkungan Hidup Daerah Provinsi Sumatera Barat 2011. Bapedalda Provinsi Sumatera Barat. Padang.

Alongi, D.M. 2002. Present state and future of the new world's mangrove forests. Environmental Conservation 29 (3): 331-349.

Blanco, J.F. and J.R. Cantera. 1999. The vertical distribution of mangrove Gastropods and environmental factors relative to tide level at Buena Ventura Bay, Pacific Coast of Colombia. Bulletin of Marine Science 65 (3) : 617-630.

Budiman, A. 1991. Penelaahan beberapa gatra ekologi moluska bakau Indonesia. Disertasi. Jakarta. Universitas Indonesia.

Brower, J.E. and J.H. Zar. 1977. Field and Laboratory Methods for Genusl Ecology. 2nd edition. Dubuque, IA. Wm.C. Brown Publishers.

Carpenter, K.E. and Niem, V.H. 1998. The living marine resources of the Western Central Pacific Volume 1: Seaweeds, corals, bivalves and gastropods. FAO Species Identification Guide for Fishery purposes. Rome.

Dewiyanti, I. 2004. Struktur Komunitas Moluska (Gastropodan dan Bivalvia) Serta Asosiasinya Pada Ekosistem Mangrove di Kawasan Pantai Ulee-Lheue, Banda Aceh,
Indeks keanekaragaman Gastropoda pada akar mangrove di Pulau Sirandah berkisar antara 0,77 sampai 1,42 .

\section{Ucapan Terima Kasih}

Ucapan terima kasih ditujukan kepada Ibu Nofrita, M.Si, Bapak Dr. Jabang Nurdin dan Dr. Rizaldi yang telah memberi saran dan masukan dalam penelitian ini.

NAD. Skripsi. Bogor. Institut Pertanian Bogor.

Dewiyanti, I., and S. Karina, 2012. Diversity of Gastropods and Bivalves in mangrove ecosystem rehabilitation areas in Aceh Besar and Banda Aceh districts, Indonesia. Aquaculture, Aquarium, Conservation \& Legislation 5(2):5559.

Frith, D.W. 1977. A premiliary list of macrofauna from a mangrove forest and adjacent biotipes at Surin Island, Western Peninsular Thailand. Pukhet Marine Biology Centre Research Bulletin. 17:1-14.

Giesen, W., S.Wulffraat, M.Zieren and L.Scholten. 2007. Mangrove Guidebook for Southeast Asia. Thailand. Dharmasarn Co., Ltd. FAO and Wetlands International.

Hartoni dan Agussalim. 2013. Komposisi dan Kelimpahan Moluska (Gastropoda dan Bivalvia) di Ekosistem Mangrove Muara Sungai Musi Kabupaten Banyuasin Provinsi Sumatera Selatan. Maspari Journal 5(1), 6-15.

Jutting, B.W.S.S. 1956. Systematic Studies on non-marine Mollusca of The Indo-australia Archipelago: Critical Revision of Javanese Freshwater Gastropoda. Treubia. 23 : 259-267.

Kamal, E., L. Hermalena, R. Tamin dan M.L. Suardi. 2005. Mangrove Sumatera Barat. Pusat Kajian Mangrove dan Kawasan Pesisir. Padang. Universitas Bung Hatta. 
Macintosh, D.J., E.C. Ashton, and S. Havanon. 2002. Mangrove rehabilitation and ntertidal biodiversity: a study in the Ranong mangrove ecosystem, Thailand. Estuarine, Coastal and Shelf Science 55 : 331-345.

Magurran, A,E. 2004. Measuring Biology Diversity. UK. Blackwell Science Ltd.

Odum, E.P. 1998. Dasar-Dasar Ekologi Edisi Ketiga. Jogjakarta. Gadjah Mada University Press.

Reid, D.G. 1984. The Systematics and Ecology of the Mangrove-Dwelling Littorina species (Gastropoda: Littorinidae) in the Indo-Pacific). Thesis. Australia. James cook University of North Queensland.

Reid, D.G. 2004. The Genus Cerithidea Swainson, 1840 (Gastropoda: Potamididae) in the Indo-West
Pacific Region. Zootaxa 3773(1): 001-065.

Sasekumar, A. 1974. Distribution of macrofauna on a Malayan mangrove shore. Journal of Animal Ecology 43(1) : 51-69.

Suwondo, E. Febrita, dan F. Sumati 2005. Struktur Komunitas Gastropoda di Hutan Mangrove, Kepulauan Mentawai, Sumatera Barat. Jurnal Biogenesis 2 (1) : 25-29.

Tapilatu, Y. dan D. Pelasula. 2012. Biota Penempel yang Berasosiasi dengan Mangrove di Teluk Ambon Bagian Dalam. Jurnal Ilmu dan Teknologi Kelautan Tropis 4(2). 267-279.

Tis'in, M. 2008. Tipologi Mangrove dan Keterkaitannya dengan populasi gastropoda Littorina neritoides (LINNE, 1758) di Kepulauan Tanakeke, Kabupaten Takalar, Sulawesi Selatan. Tesis. Bogor. Institut Pertanian Bogor. 